\title{
Factors Associated with Severe Leptospirosis, Martinique, 2010-2013
}

\author{
Patrick Hochedez, Rafaelle Theodose, \\ Claude Olive, Pascale Bourhy, Guillaume Hurtrel, \\ Nicolas Vignier, Hossein Mehdaoui, \\ Ruddy Valentino, Roland Martinez, \\ Jean-Marie Delord, Cécile Herrmann, \\ Isabelle Lamaury, Raymond Césaire, \\ Mathieu Picardeau, André Cabié
}

To identify factors associated with disease severity, we examined 102 patients with quantitative PCR-confirmed leptospirosis in Martinique during 2010-2013. Associated factors were hypotension, chest auscultation abnormalities, icterus, oligo/anuria, thrombocytopenia, prothrombin time $<68 \%$, high levels of leptospiremia, and infection with L. interrogans serovar Icterohaemorrhagiae/Copenhageni.

$\mathrm{L}$ eptospirosis is a bacterial zoonosis of worldwide distribution; incidence is highest in impoverished populations in developing countries and tropical regions (1). Humans are usually infected through contact with water or soil contaminated with the urine of carrier animals (2). The disease is caused by pathogenic strains of bacteria of the genus Leptospira, which is composed of 21 genomic species; 9 of them are pathogenic and comprise $>200$ serovars (3). To reduce the effects of severe leptospirosis, early diagnosis and prompt triage of high-risk patients is critical. Quantitative PCR (qPCR) might provide rapid diagnosis during the acute stage of the illness, offers the ability to measure the level of leptospiremia, and provides genomic identification (4-6). Our objectives were to determine if qPCR-determined leptospiremia was associated with severe evolution of the disease and to identify clinical and biological variables associated with severity.

Author affiliations: Centre Hospitalier Universitaire de Martinique,

Fort de France, Martinique, France (P. Hochedez, R. Theodose,

C. Olive, G. Hurtrel, N. Vignier, H. Mehdaoui, R. Valentino,

R. Césaire, A. Cabié); Université des Antilles et de la Guyane,

Fort de France, Martinique, and Pointe à Pitre, Guadeloupe,

France (P. Hochedez, R. Theodose, C Olive, C. Herrmann,

I. Lamaury, R. Césaire); Institut Pasteur, Paris, France (P. Bourhy,

M. Picardeau); Centre Hospitalier Universitaire Avicenne, Bobigny,

France (N. Vignier); Centre Hospitalier de Trinité, Trinité, Martinique

(R. Martinez); Centre Hospitalier du Lamentin, Lamentin,

Martinique (J.-M. Delord); Centre Hospitalier Universitaire de

Pointe à Pitre, Guadeloupe (C. Herrmann, I. Lamaury); Institut

National de la Santé et de la Recherche Medicale, Paris (A. Cabié)

DOI: http://dx.doi.org/10.3201/eid2112.141099

\section{The Study}

From December 2010 through February 2013, blood samples were obtained from a cohort of 102 adult patients with qPCR-confirmed leptospirosis at the University Hospital of Martinique. The study was approved by the French ethics committee. At the time of admission, clinical characteristics, biological findings, and potential exposures were recorded. Severe leptospirosis was defined by the presence of $\geq 1$ of the following: shock treated with vasoactive drugs, acute renal failure requiring dialysis, internal bleeding requiring blood transfusion, respiratory insufficiency requiring mechanical ventilation, or death.

After EDTA-treated plasma was concentrated by centrifugation, DNA was extracted and used to perform a SYBR green assay (Bio-Rad, Hercules, CA, USA) selective for $l f b l$ as previously described (7-9). The sensitivity of the assay was evaluated by using DNA extracted from 10 -fold dilutions of reference strains (at $10^{7}-10^{2}$ leptospires $/ \mathrm{mL}$ ) belonging to L. borgpetersenii, L. interrogans, and L. kirschneri. Serum samples were subjected to microscopic agglutination testing, and 45 available samples of Leptospira were cultured as previously described (8). Genomic DNA was extracted from cultures or from human plasma, and then Leptospira species and subspecies were identified as previously described $(10,11)$.

Statistical analyses were performed by using Stata software version 12 (StataCorp LP, College Station, TX, USA). Leptospiremia was log-transformed. Receiver operating characteristics curve analysis was used to determine the critical threshold for leptospiremia as the marker for severity. Logistic regression was used to identify factors associated with severity. Continuous variables were summarized by using median, first quartile, and third quartile and compared by using nonparametric tests (Mann-Whitney or Kruskal-Wallis, as appropriate). A p value of $<0.05$ was considered statistically significant.

Most $(86.3 \%)$ of the 102 patients were men; median age was 49 (37-57) years. Of these patients, 89 were hospitalized, 23 required treatment in intensive care units, and $12(11.7 \%)$ had severe leptospirosis according to our clinical definition. The median delay between symptom onset and qPCR diagnosis was 3 days first quartile and third quartile $=2,5$ days, respectively); blood tests were sampled from day 1 through day 11 after symptom onset, before administration of antimicrobial drugs. The median delay between symptom onset and antimicrobial drug receipt was $4(3,5)$ days. This delay did not differ significantly among patients with severe disease. 


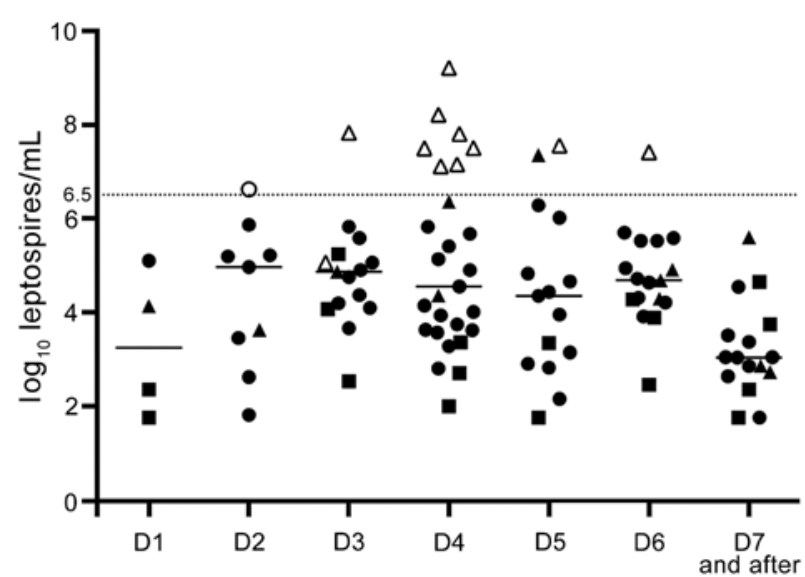

Figure 1. Leptospiremia in 102 patients with quantitative PCR-confirmed leptospirosis and day of sample collection since symptom onset, Martinique, 2010-2013. Each symbol (triangle, circle, or square) represents the leptospiremia of 1 leptospirosis patient on the day when the sample was collected. D indicates day since symptom onset. Open symbols indicate severe cases; closed symbols indicate nonsevere cases. Triangles correspond to Leptospira interrogans species, circles to other identified species, and squares to cases without genomic identification. Dotted line indicates the threshold for severe diseases determined by receiver operating characteristic curve analysis.

Leptospiremia, determined by qPCR (Figure 1), was significantly higher among patients with severe disease $\left(7.49 \log _{10}[7.13,7.81]\right.$ vs. $4.16 \log _{10}[3.14$, 4.93]; $\mathrm{p}=0.00001)$. Among those with severe disease, 9 had shock requiring vasoactive drugs, 8 had pulmonary involvement requiring mechanical ventilation, 8 had internal bleeding requiring blood transfusion, and 7 had acute renal failure requiring dialysis. No patient died. The median length of evolution before occurrence of severe leptospirosis was $3(3,4)$ days. Using a receiver operating characteristic curve analysis,

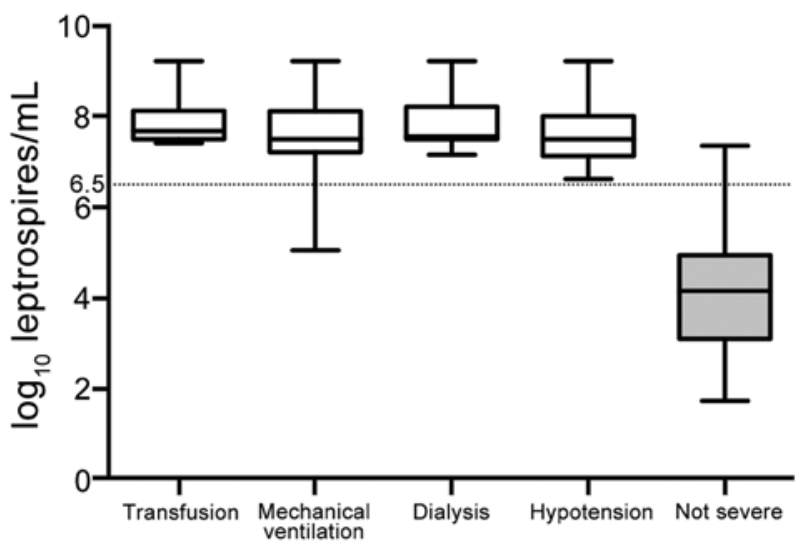

Figure 2. Distribution of leptospiremia among 102 patients with quantitative PCR-confirmed leptospirosis, grouped by severity criteria, Martinique, 2010-2013. Criteria that met our clinical definition for severe leptospirosis were shock treated with vasoactive drugs, acute renal failure requiring dialysis, internal bleeding requiring blood transfusion (e.g., alveolar hemorrhage), and respiratory insufficiency requiring mechanical ventilation or death during hospitalization. Horizontal lines in box-and-whisker plots indicate (top to bottom) maximum value, third quartile, median (second quartile), first quartile, minimum value.Dotted line indicates the threshold for severe diseases determined by receiver operating characteristic curve analysis.

we found a critical threshold of $6.5 \log _{10}$ leptospires/ $\mathrm{mL}$ that could be considered severe leptospirosis (Figures 1, 2). Except for acute renal failure, all complications were associated with a higher level of leptospiremia (online Technical Appendix Table 1, http://wwwnc.cdc.gov/ EID/article/21/12/14-1099-Techapp1.pdf).

The only epidemiologic characteristic associated with severity was presence of rats in the house or the surrounding vicinity $(\mathrm{p}=0.02)$. Clinical and biological findings recorded at admission were associated with severity (Tables $1,2)$ as follows: hypotension, chest auscultation abnormalities, icterus, oligo/anuria, bilirubin $>49 \mu \mathrm{mol} / \mathrm{L}$, creatinine $>154 \mu \mathrm{mol} / \mathrm{L}$, creatine phosphokinase $>443 \mathrm{U} / \mathrm{L}, \mathrm{C}$-reactive

\begin{tabular}{|c|c|c|c|c|}
\hline Characteristic & $\begin{array}{c}\text { All patients, } n=102, \\
\text { no. }(\%)\end{array}$ & $\begin{array}{c}\text { Patients with severe } \\
\text { disease, } \mathrm{n}=12, \mathrm{no} .(\%)\end{array}$ & $\begin{array}{l}\text { Patients with nonsevere } \\
\text { disease, } n=90, \text { no. }(\%)\end{array}$ & $p$ value \\
\hline Fever $>38^{\circ} \mathrm{C}$ & $88(86.3)$ & $9(75)$ & $79(87.8)$ & 0.364 \\
\hline Hypotension* & $10(9.8)$ & $5(41.7)$ & $5(5.6)$ & 0.002 \\
\hline Cough & $12(11.8)$ & $3(25)$ & $9(10)$ & 0.148 \\
\hline Abnormalities at chest auscultation & $7(6.9)$ & $4(33.3)$ & $3(3.3)$ & 0.003 \\
\hline Abdominal pain & $30(29.4)$ & $5(41.7)$ & $25(27.8)$ & 0.329 \\
\hline Vomiting & $42(41.2)$ & $5(41.7)$ & $37(41.1)$ & 1 \\
\hline Diarrhea & $30(29.4)$ & $3(25)$ & $27(30)$ & 1 \\
\hline Icterus & $39(38.2)$ & $9(75)$ & $30(33.3)$ & 0.009 \\
\hline Conjunctival suffusion & $20(19.6)$ & $1(8.3)$ & $19(21.1)$ & 0.45 \\
\hline Consciousness disorders & $2(1.6)$ & $1(8.3)$ & $1(1.1)$ & 0.2 \\
\hline Hemorrhage & $6(5.9)$ & $1(8.3)$ & $5(5.6)$ & 0.54 \\
\hline 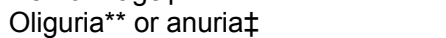 & $8(7.8)$ & $5(41.7)$ & $3(3.3)$ & 0.0001 \\
\hline
\end{tabular}

*Systolic blood pressure $<90 \mathrm{~mm} \mathrm{Hg}$.

†Hemoptysis, hematuria, bleeding of the gums, or hematemesis.

$\ddagger<500 \mathrm{~mL}$ urine/day. 
Table 2. Initial laboratory findings among 102 patients with quantitative PCR-confirmed leptospirosis, by disease severity, Martinique, 2010-2013

\begin{tabular}{|c|c|c|c|c|}
\hline Initial laboratory findings* & $\begin{array}{c}\text { All patients, } n=102 \text {, } \\
\text { no. }(\%)\end{array}$ & $\begin{array}{c}\text { Patients with severe } \\
\text { disease, } n=12, \text { no. }(\%)\end{array}$ & $\begin{array}{l}\text { Patients with nonsevere } \\
\text { disease, } n=90, \text { no. }(\%)\end{array}$ & $\mathrm{p}$ value \\
\hline \multicolumn{5}{|l|}{ Bilirubin } \\
\hline$\mu \mathrm{mol} / \mathrm{L}(\mathrm{Q} 1, \mathrm{Q} 3)$ & $20(12,49)$ & $56.5(35.5,103)$ & $18(12,38)$ & 0.0035 \\
\hline$>49 \mu \mathrm{mol} / \mathrm{L}$, no./total $(\%)$ & 25/99 (25.2) & $7 / 12(58.3)$ & $18 / 87(20.7)$ & 0.01 \\
\hline \multicolumn{5}{|l|}{ Creatinine } \\
\hline$\mu \mathrm{mol} / \mathrm{L}(\mathrm{Q} 1, \mathrm{Q} 3)$ & $104(88,154)$ & $169.5(132.5,217.5)$ & $100(87,137)$ & 0.0084 \\
\hline$>154 \mu \mathrm{mol} / \mathrm{L}$, no./total $(\%)$ & $26 / 101(25.7)$ & $7 / 12(58.3)$ & $19 / 89(21.3)$ & 0.011 \\
\hline \multicolumn{5}{|l|}{ Urea nitrogen $(\mathrm{mmo} / \mathrm{LI})$} \\
\hline $\mathrm{mmol} / \mathrm{L}(\mathrm{Q} 1, \mathrm{Q} 3)$ & $5.7(4.2,9.3)$ & $10.1(8,18.5)$ & $5.5(4,8.6)$ & 0.0068 \\
\hline$>9.3, \mathrm{mmol} / \mathrm{L}$, no./total $(\%)$ & $21 / 84(25)$ & $4 / 8(50)$ & $17 / 76(22.4)$ & 0.103 \\
\hline \multicolumn{5}{|l|}{ Creatine phosphokinase } \\
\hline U/L (Q1, Q3) & $170(70,443)$ & $953(204,1332)$ & $145(64,390)$ & 0.0202 \\
\hline$>443$ U/L, no./total (\%) & $19 / 75(25.3)$ & $5 / 9(55.6)$ & $14 / 66(21.2)$ & 0.041 \\
\hline \multicolumn{5}{|l|}{ C-reactive protein } \\
\hline mg/L (Q1, Q3) & $188.5(108,282)$ & $338.5(197.5,464.5)$ & $177.9(89,265)$ & 0.0017 \\
\hline$>282$ mg/L, no./total (\%) & $26 / 102(25.5)$ & $7 / 12(58.3)$ & $19 / 90(21.1)$ & 0.011 \\
\hline Potassium, mmol/ L (Q1, Q3) & $3.7(3.4,4.1)$ & $3.75(3.35,4.15)$ & $3.7(3.3,4.1)$ & 0.8 \\
\hline Sodium, $\mathrm{mmo} / \mathrm{L}(\mathrm{Q} 1, \mathrm{Q} 3)$ & $134(132,136)$ & $134(131.5,135)$ & $134(132,136)$ & 0.44 \\
\hline Aspartate aminotransferase, U/L (Q1, Q3) & $61.5(32,102)$ & $73.5(59,126.5)$ & $57.5(31,102)$ & 0.19 \\
\hline Alanine aminotransferase, U/L(Q1, Q3) & $55(30,96)$ & $49(33.5,74.5)$ & $55(30,99)$ & 0.69 \\
\hline \multicolumn{5}{|l|}{ Hemoglobin } \\
\hline g/dL (Q1, Q3) & $13.2(12.2,14.5)$ & $12.2(11.6,13)$ & $13.3(12.4,14.7)$ & 0.027 \\
\hline$<12.2 \mathrm{~g} / \mathrm{dL}$, no./total $(\%)$ & $26 / 102(25.5)$ & $6 / 12(50)$ & $20 / 90(22.2)$ & 0.071 \\
\hline Leukocytes, $\times 10^{9}$ cells/L (Q1, Q3) & $8.51(6.2,10.9)$ & $10.3(9.1,11.4)$ & $7.8(6.1,10.5)$ & 0.07 \\
\hline \multicolumn{5}{|l|}{ Lymphocytes } \\
\hline$\times 10^{9}$ cells/L (Q1, Q3) & $0.7(0.49,1)$ & $0.5(0.2,0.7)$ & $0.7(0.5,1)$ & 0.043 \\
\hline$<0.49 \times 10^{9} \mathrm{cells} / \mathrm{L}$, no./total $(\%)$ & $24 / 92(26)$ & $4 / 8(50)$ & $20 / 84(23.8)$ & 0.19 \\
\hline \multicolumn{5}{|l|}{ Platelets } \\
\hline Concentration, × 109/L (Q1, Q3) & $138(92,183)$ & $70.5(32.5,115)$ & $141(99,191)$ & 0.0011 \\
\hline$<92 \times 10^{9} / \mathrm{L}$, no./total $(\%)$ & $26 / 101(25.7)$ & $7 / 12(58.3)$ & $19 / 89(21.3)$ & 0.011 \\
\hline \multicolumn{5}{|l|}{ Prothrombin time } \\
\hline \% (Q1, Q3) & $74(68,90.5)$ & $66.5(56,74.5)$ & $75.5(69,91)$ & 0.0166 \\
\hline$<68 \%$, no./total $(\%)$ & $20 / 76(26.3)$ & $7 / 12(58.3)$ & $13 / 64(20.3)$ & 0.011 \\
\hline
\end{tabular}

protein $>282 \mathrm{mg} / \mathrm{L}$, hemoglobin $<12.2 \mathrm{~g} / \mathrm{dL}$, lymphocytes $<0.49 \times 10^{9}$ cells $/ \mathrm{L}$, platelets $<92 \times 10^{9} / \mathrm{L}$, and prothrombin time $<68 \%$.

Molecular typing of genomic DNA was performed from the 102 acute-phase blood samples (online Technical Appendix Table 2). Leptospire species determination was successful for $85(83 \%)$ patients and corresponded to 1 of the following 6 pathogenic species: L. interrogans $(\mathrm{n}=23), L$. santarosai $(\mathrm{n}=22), L$. borgpetersenii $(\mathrm{n}=$ 18), L. kirschneri $(\mathrm{n}=15)$, L. kmetyi $(\mathrm{n}=4)$, and L. noguchii $(\mathrm{n}=3)$. Among the genomic species identified, L. interrogans was associated with severity $(\mathrm{p}=0.001)$, highest level of leptospiremia $(p=0.0001)$, and previous exposure to rats $(p=0.02)$. The level of leptospiremia in specimens for which species was not identified was significantly lower $(\mathrm{p}=0.0001)$. The median melting peak for $L$. interrogans strains was $83.1^{\circ} \mathrm{C}\left(82.8^{\circ} \mathrm{C}, 83.4^{\circ} \mathrm{C}\right)$, which differed significantly from that of other species, for which the median melting peak was $85^{\circ} \mathrm{C}\left(84^{\circ} \mathrm{C}, 85.9^{\circ} \mathrm{C}\right)$ $(\mathrm{p}=0.0001)$.

Microscopic agglutination testing enabled identification of the putative serogroups (highest titer $>400$ ) for $70(68.6 \%)$ patients; the 3 most frequently identified serogroups were Icterohaemorrhagiae $(\mathrm{n}=39)$, Ballum $(\mathrm{n}=11)$, and Celledoni $(\mathrm{n}=10)$. Serogroup Icterohaemorrhagiae can be subdivided into serovars Icterohaemorrhagiae/Copenhageni $(n=20)$ and Bogvere $(n=10)$; the remaining 9 serogroups cannot be unambiguously typed at the serovar level. Serovar Icterohaemorrhagiae/Copenhageni was identified for 11 of the 12 patients with severe disease $(p=0.03)$. The identification of the putative serogroup was not possible for 32 patients (online Technical Appendix Table 3).

\section{Conclusions}

This prospective study enabled us to report the potential contribution of qPCR to timely diagnosis and leptospirosis severity evaluation at the point of care in a disease-endemic area. We based our classification of severity on treatment-related criteria to reflect everyday patient management, as previously reported $(12,13)$. The fact that no patient died could be associated with factors such as reduced diagnosis time and early treatment. Currently, only qPCR enables unequivocal diagnosis during 
the acute phase of illness, when antimicrobial drugs are most likely to have the greatest benefit $(6,14)$. Our results show a strong association between leptospiremia levels and disease severity. A lower critical threshold was reported in New Caledonia, and differences between critical thresholds may be associated with the variability of virulence among serovars, host factors, or qPCR technique (13).

The samples used for qPCR diagnosis were also used for direct Leptospira genomic identification, although molecular typing performance was impaired for samples with the lowest leptospiremia, as previously reported (15). The factors significantly associated with severity were infection with the species L. interrogans, the serogroup Icterohaemorrhagiae, and the presence of rats (usual carriers of that serogroup). In that context, melting curve analysis of the assay may provide rapid and useful additional information because it can differentiate between $L$. interrogans and other pathogenic species $(7,9)$. The potential correlation between disease severity and serogroup Icterohaemorrhagiae has been reported in other tropical islands, and our results also emphasize the need for public health action to control rodents $(12,13)$.

qPCR can be used for rapid diagnosis of acute leptospirosis and may provide timely information useful for evaluation of disease severity. Use of qPCR to determine leptospiremia seems increasingly accessible and should be evaluated in other disease-endemic areas. Whether high levels of leptospiremia are associated with factors such as pathogen virulence characteristics or host factors should also be explored.

\section{Acknowledgments}

We thank Olivier Verlaeten and Ludovic Jeanneau, who introduced the qPCR technique in the University Hospital of Fort de France; Dorothée Haug and the technical staff at the Service de Bactériologie of the University Hospital of Fort-de-France; Janick Jean-Marie and the staff at the Centre d'Investigation Clinique et d'Epidémiologie Clinique Antilles-Guyane (Institut National de la Santé et de la Recherche Médicale CIE 802); Christopher Pappas for editorial assistance; and Eric Caumes for critical review of the manuscript. We also thank the French Ministry of Health with the participation of the Groupement Interrégional de Recherche Clinique et d'Innovation Sud-Ouest Outre-Mer for funding and the Direction de la Recherche Clinique et de Innovation of the University Hospital of Fort-de-France, Martinique, France, for methodologic support.

Dr. Hochedez is a physician in the Infectious and Tropical Diseases Unit at the teaching hospital of Fort de France, Martinique, French West Indies. His primary research interests are surveillance and epidemiology of leptospirosis, and travel-associated diseases.

\section{References}

1. Levett PN. Leptospirosis. Clin Microbiol Rev. 2001;14:296-326. http://dx.doi.org/10.1128/CMR.14.2.296-326.2001

2. Bharti AR, Nally JE, Ricaldi JN, Matthias MA, Diaz MM, Lovett MA, et al. Leptospirosis: a zoonotic disease of global importance. Lancet Infect Dis. 2003;3:757-71. http://dx.doi.org/ 10.1016/S1473-3099(03)00830-2

3. Ko AI, Goarant C, Picardeau M. Leptospira: the dawn of the molecular genetics era for an emerging zoonotic pathogen. Nat Rev Microbiol. 2009;7:736-47. http://dx.doi.org/10.1038/ nrmicro2208

4. Bourhy P, Herrmann Storck C, Theodose R, Olive C, Nicolas M, Hochedez P, et al. Serovar diversity of pathogenic Leptospira circulating in the French West Indies. PLoS Negl Trop Dis. 2013;7:e2114. http://dx.doi.org/10.1371/journal.pntd.0002114

5. Truccolo J, Serais O, Merien F, Perolat P. Following the course of human leptospirosis: evidence of a critical threshold for the vital prognosis using a quantitative PCR assay. FEMS Microbiol Lett. 2001;204:317-21. http://dx.doi.org/10.1111/ j.1574-6968.2001.tb10904.x

6. World Health Organization. Human leptospirosis: guidance for diagnosis, surveillance and control. Geneva: The Organization; 2003. p. $9-16$

7. Merien F, Portnoi D, Bourhy P, Charavay F, Berlioz-Arthaud A, Baranton G. A rapid and quantitative method for the detection of Leptospira species in human leptospirosis. FEMS Microbiol Lett. 2005;249:139-47. http://dx.doi.org/10.1016/j.femsle.2005.06.011

8. Hochedez P, Escher M, Decoussy H, Pasgrimaud L, Martinez R, Rosine J, et al. Outbreak of leptospirosis among canyoning participants, Martinique, 2011. Euro Surveill. 2013;18:20472.

9. Bourhy P, Bremont S, Zinini F, Giry C, Picardeau M. Comparison of real-time PCR assays for detection of pathogenic Leptospira spp. in blood and identification of variations in target sequences. J Clin Microbiol. 2011;49:2154-60. http://dx.doi.org/10.1128/ JCM.02452-10

10. Bourhy P, Collet L, Clement S, Huerre M, Ave P, Giry C, et al. Isolation and characterization of new Leptospira genotypes from patients in Mayotte (Indian Ocean). PLoS Negl Trop Dis. 2010;4:e724. http://dx.doi.org/10.1371/journal.pntd.0000724

11. Mérien F, Amouriaux P, Perolat P, Baranton G, Saint Girons I. Polymerase chain reaction for detection of Leptospira spp. in clinical samples. J Clin Microbiol. 1992;30:2219-24.

12. Herrmann-Storck C, Saint-Louis M, Foucand T, Lamaury I, Deloumeaux J, Baranton G, et al. Severe leptospirosis in hospitalized patients, Guadeloupe. Emerg Infect Dis. 2010;16: 331-4. http://dx.doi.org/10.3201/eid1602.090139

13. Tubiana S, Mikulski M, Becam J, Lacassin F, Lefevre P, Gourinat AC, et al. Risk factors and predictors of severe leptospirosis in New Caledonia. PLoS Negl Trop Dis. 2013;7:e1991. PLoS Negl Trop Dis. 2013;7:e1991. http://dx.doi.org/10.1371/journal.pntd.0001991

14. Merien F, Baranton G, Perolat P. Comparison of polymerase chain reaction with microagglutination test and culture for diagnosis of leptospirosis. J Infect Dis. 1995;172:281-5. http://dx.doi.org/10.1093/infdis/172.1.281

15. Agampodi SB, Moreno AC, Vinetz JM, Matthias MA. Utility and limitations of direct multi-locus sequence typing on qPCR-positive blood to determine infecting Leptospira strain. Am J Trop Med Hyg. 2013;88:184-5. http://dx.doi.org/10.4269/ ajtmh.2012.12-0526

Address for correspondence: Patrick Hochedez, Service des Maladies Infectieuses et Tropicales, Centre Hospitalier Universitaire de Martinique, BP 632, 97261 Fort de France, Martinique, France; email: patrick.hochedez@chu-fortdefrance.fr 